폐유리와 산화 그래핀을 사용한 시멘트 모르타르의 물성 연구

\author{
김경석 · \&추용식
}

한국세라믹기술원 에너지환경본부 에너지효율소재센터

\title{
Physical Characteristics of Cement Mortar Prepared Using Waste Glass and Graphene Oxide
}

\author{
Kyoungseok Kim and ${ }^{\S}$ Yongsik Chu \\ Energy Efficient Materials Team, Energy \& Environmental Division, KICET
}

\begin{abstract}
요 약
본 연구에서는 폐유리를 골재로 재활용하고자 폐유리와 산화 그래핀을 사용한 시멘트 모르타르의 압축강도 및 길이 변화율 등을 검토하였다. 3 일 및 7일 압축강도는 일반 모래 대체용 폐유리 사용량이 증가할수록 상승하였다. 특히, 폐유리 사용량이 $10 \sim 50 \%$ 범 위일 경우, 압축강도는 큰 폭으로 상승하는 경향을 나타내었다. 더불어 폐유리 $50 \%$ 조건에서도 산화 그래핀의 첨가량이 증가됨에 따라 압축강도가 상승하였으며, $0.2 \%$ 를 첨가하였을 때, 압축강도는 $42.6 \mathrm{~N} / \mathrm{mm}^{2}$ 이었다. 폐유리의 사용량이 증가됨에 따라 모르타 르의 길이 변화율은 증가하였으나, $50 \%$ 이상에서는 길이변화율이 감소하는 경향도 나타내었다. 폐유리 사용량 $50 \%$ 모르타르에서 는 산화 그래핀 첨가량이 증가할수록 길이 변화율이 감소하는 경향을 나타내었으며, 이는 산화 그래핀의 시멘트 수화반응 촉진작용 과 이온이동 억제효과로 추정되었다.
\end{abstract}

주제어 : 폐유리, 산화 그래핀, 압축강도, 길이 변화율, 알칼리-실리카 반응

\begin{abstract}
This study investigated on the compressive strength and the length change test with using the waste glass and graphene oxide for recycling the waste glass as the aggregate. Curing on 3-day and 7-day, the compressive strength was enhanced as the usage of waste glass was increased. Especially, the huge difference in the compressive strength was observed when the amount of substituting on the waste glass was used on $10 \sim 50 \%$. With $50 \%$ of waste glass condition, the compressive strength was portionally enhanced as the usage of graphene oxide was increased and its value was $42.6 \mathrm{~N} / \mathrm{mm}^{2}$ with $0.2 \%$ of graphene oxide. In terms of the length change test, the use of high content of waste glass led length change value to increase, but it was dropped down as the portion of waste glass was above $50 \%$. Furthermore, in the case of using $50 \%$ of waste glass, the use of high amount of graphene oxide tended to decrease the length change value. That is, graphene oxide may contribute on boosting the cement hydration reaction and blocking the ion's movement.
\end{abstract}

Key words : waste glass, graphene oxide(GO), compressive strength, length change, alkali-silica reaction(ASR)

\footnotetext{
- Received : October 25, 2019 - Revised : November 13, 2019 · Accepted : November 22, 2019

$\S$ Corresponding Author : Yong Sik Chu (E-mail : yschu@kicet.re.kr)

Energy \& Environmental Division, Korea Institute of Ceramic Engineering \& Technology, 101, Soho-ro, Jinju-si, Gyeongsangnam-do 52851, Korea

(C) The Korean Institute of Resources Recycling. All rights reserved. This is an open-access article distributed under the terms of the Creative Commons Attribution Non-Commercial License (http://creativecommons.org/licenses/by-nc/3.0/), which permits unrestricted non-commercial use, distribution and reproduction in any medium, provided the original work is properly cited.
} 


\section{1. 서 론}

2018년 11월 환경부에서는 “자원의 절약과 재활용촉 진에 관한 법률” (자원재활용법, 법률 제 15101호)을 개정하여 폐기물 발생을 억제하고 재활용을 촉진하고자 하였다. 이는 자원을 순환적으로 이용하여 환경 보전과 국민경제의 건전한 발전에 이바지하고자 하는 것이다1). 폐기물 관리법 시행규칙에는 폐기물 재활용 기준 및 구 체적인 재활용 방법을 제시하고 있으며, 폐유리(유리병 등)의 경우 파쇄 및 분쇄하여 유리제품이나 건축.토목 자재의 원료로 가공하는 경우로 명시하고 있다2). 한편 국내 폐유리병의 발생량은 연간 약 42 만톤이나, 재활용 실적은 약 30 만톤(재활용률 약 $70 \%$ ) 수준에 불과하다 ${ }^{3)}$. 이는 유리의 색에 따라 선별 사용해야 하나, 분리·선별 이 용이하지 못하기 때문이다. 일반적으로 유리병 색상 은 착색제의 종류 및 함량 등에 따라 달라지며, 대체로 $\mathrm{Na}_{2} \mathrm{O} \quad 13 \sim 15 \%, \mathrm{~K}_{2} \mathrm{O} 0.5 \sim 1.5 \%, \mathrm{SiO}_{2} 65 \sim 70 \%$ 수 준이 함유되어 있다 ${ }^{3)}$. 대부분의 화학성분이 알칼리 및 실리카로 구성된 폐유리를 모르타르 및 콘크리트에 적 용하기 위해서는 알칼리 실리카 반응 (Alkali Silica Reaction; ASR)에 주의해야 한다 ${ }^{4)}$.

모르타르 및 콘크리트에 존재하는 알칼리 성분은 알 칼리 실리카 반응을 발생시켜 구조체의 균열·팽창 및 박리현상 등을 야기하는 것으로 알려져 있다 ${ }^{4,5,6)}$. 특히 알칼리 함량이 높은 폐유리를 골재로 사용할 경우, $\mathrm{ASR}$ 이 더욱 가속화되어 모르타르 및 콘크리트 적용에 큰 어려움이 있다. $\mathrm{ASR}$ 의 기본 메커니즘은 시멘트 경 화체 공극에 존재하는 알칼리 용액 속에 $\mathrm{OH}^{-}$와 $\mathrm{Na}^{+}$ 이온이 실리카와 반응하여 겔을 생성하는 것이며, 이는 아래와 같은 기본 반응식에 따라 생성된다고 알려져 있다6).

$$
\begin{aligned}
& -\mathrm{Si}-\mathrm{O}-\mathrm{Si}+\mathrm{OH}^{-} \rightarrow-\mathrm{Si}-\mathrm{O}^{-}+\mathrm{H}_{2} \mathrm{O} \\
& \mathrm{Si}-\mathrm{O}^{-}+\mathrm{Na}^{+} \rightarrow-\mathrm{Si}-\mathrm{O}+\mathrm{Na}
\end{aligned}
$$

일반적으로 폐유리 등의 비정질 실리카 용해도는 결 정질 실리카의 10 배에서 20 배에 이르는 것으로 발표되 고 있다 ${ }^{7)}$. 이는 용액의 $\mathrm{OH}^{-}$이온 농도가 높아지면 비 정질 실리카의 실록산 결합이 절단되기 때문이며, 이때 용출된 실리카는 $\mathrm{OH}^{-}$의 농도가 높아질수록 $\mathrm{Si}(\mathrm{OH})_{4}$ 라 는 모노머로 쉽게 변화된다. 이 모노머는 모르타르 또 는 콘크리트 세공용액 속에 존재하는 $\mathrm{Na}^{+}, \mathrm{Ca}^{2+}$ 등의 촉매 작용에 의해 겔 형태로 변화된다 ${ }^{8)}$. 이와 같이 형
성된 실리카 겔은 $\mathrm{ASR}$ 을 더욱 촉진시켜 모르타르 또 는 콘크리트의 과대 팽창 등을 발생시키기도 한다. 따 라서 ASR 반응을 억제하기 위한 다양한 방법이 도출 되고 있으며, 대표적 방법으로 모르타르·콘크리트 조직 을 치밀하게 제어하는 방법이 있다. 모르타르·콘크리트 조직이 치밀해지면 수분 이동이 어려워지고, 이에 따라 알칼리 및 실리카 이온 이동도 어려워지기 때문이다. 이때 치밀 조직을 만들기 위해서 실리카흠 등의 미립 충전재 및 슬래그 등의 포졸란 물질 등을 사용하기도 한다.

대표적인 nano-carbon 소재인 그래핀은 높은 비표면 적(약 $\left.2,630 \mathrm{~m}^{2} / \mathrm{g}\right)$, 높은 고유 강도 $(130 \mathrm{GPa})$, 높은 영 률 $(1.0 \mathrm{TPa})$ 과 고 전기전도 등의 특성을 보유하고 있 으며, 그래핀은 산화 그래핀, 이중 층 그래핀, 나노 리 본 등의 다양한 형태로 존재한다 ${ }^{9)}$. 산화 그래핀은 보통 흑연을 산화하여 그래핀을 얻어내는 Hummers method 로 제조되며, 산화 그래핀의 제조 공정에서 $\mathrm{KMnO}_{4}$, $\mathrm{NaNO}_{3}, \mathrm{H}_{2} \mathrm{SO}_{4}$ 등의 용액을 사용하기 때문에 거친 표 면을 가지는 것으로 알려져 있다 ${ }^{10,11)}$. 또한, 산화 그래 핀은 친수성 용매에서 시멘트 등의 세라믹 분말과 쉽게 복합화될 수 있는 성질을 가지고 있어, 모르타르·콘크 리트 분야에도 많이 사용되는 것으로 알려져 있다 ${ }^{12)}$. 이는 산화 그래핀이 시멘트 수화반응 과정에서 수화물 의 핵생성 및 핵성장을 가속화 하는 등, 수화반응을 촉 진시켜 시멘트 페이스트의 경도 및 강도 등을 상승시키 기 때문이다 ${ }^{13,14,15)}$. 또한, 산화 그래핀은 카르복시산 그 룹을 함유하고 있으며, 이는 C-S-H 또는 $\mathrm{Ca}(\mathrm{OH})_{2}$ 와 반응하여 계면에 강한 공유 결합을 형성시켜 물성 향상 에도 기여하게 된다 ${ }^{16)}$.

따라서 본 연구에서는 국내에서 폐기되는 폐유리를 골재로 사용하여 모르타르를 제조하고자 하였으며, 이 때 모르타르의 길이변화율 및 강도 특성을 분석하였다. 또한, 산화 그래핀을 첨가하여 모르타르 팽창 제어 특 성도 검토하고자 하였다.

\section{2. 실험방법}

본 연구에서는 산화 그래핀의 수화특성과 폐유리를 사용한 모르타르의 물리적 특성을 분석하기 위해 Fig. 1 과 같이 실험하였다.

산화 그래핀의 수화특성을 검토하기 위해 시멘트 페 이스트를 제조하였으며, 이때 시멘트 $100 \mathrm{~g}$, 증류수 $40 \mathrm{~g}$ 및 시멘트 중량 대비 $0.05 \%, 0.1 \%, 0.2 \%$ 의 산화 그래 


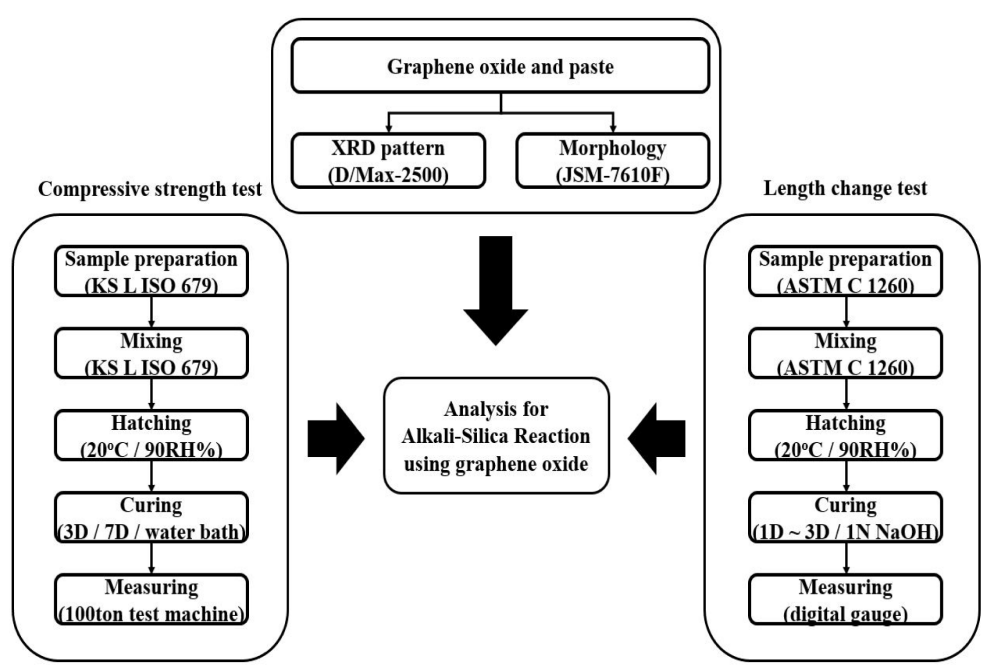

Fig. 1. Schematic diagram of experimental process.

핀을 배합하였다. 제조된 시멘트 페이스트는 각각 3 일 및 7일 동안 수중 양생하였으며, 수중 양생이 종료된 후 XRD(D/Max-2500, Rigaku社)를 사용하여 수화물의 결정구조를 분석하였으며, SEM(JSM-7610F, JEOL社)을 사용하여 미세구조도 관찰하였다.

Table 1은 압축강도 특성을 확인하기 위한 모르타르 배합설계비를 나타낸 것이다. 폐유리 및 산화 그래핀 사 용에 따른 모르타르 압축강도 특성을 확인하기 위해, 1 종 보통포틀랜드시멘트(분말도 $3,300 \mathrm{~cm}^{2} / \mathrm{g}$ ), 혼합수(증 류수), 일반 모래(8호사) 및 폐유리(병유리 파쇄분)를 사 용하였다. Table 2 와 같이 폐유리 입도는 $4.75 \sim 2.36$ $\mathrm{mm}, \quad 2.36 \sim 1.18 \mathrm{~mm}, \quad 1.18 \sim 0.60 \mathrm{~mm}, \quad 0.60 \sim 0.30$ $\mathrm{mm}, 0.30 \sim 0.15 \mathrm{~mm}$ 수준으로 분리하였으며, 입도별 구성비는 $10 \%, 25 \%, 25 \%, 25 \%, 15 \%$ 로 고정하였다. 시멘트 $450 \mathrm{~g}$, 증류수 $225 \mathrm{~g}$, 일반 모래와 폐유리는 $1,350 \mathrm{~g}$ 으로 고정하였으며, KS L ISO 679 규격(시멘트 의 강도시험 방법)에 따라 실험을 진행하였다. 이때 일 반 모래와 폐유리의 배합비는 각각 $1: 9,3: 7,5: 5,7: 3$, 9:1로 제어하였다. 이외에도 일반 모래와 폐유리 배합비 를 $5: 5$ 로 고정하고, 산화 그래핀을 시멘트 중량 대비 $0.05 \%, 0.1 \%, 0.2 \%$ 첨가하여 모르타르를 추가 제조 (No. 4-1 4-3)하였다. 제조 모르타르는 3일 및 7일

Table 1. Mixing ratio for manufacturing mortar for compressive strength test

(Unit : g)

\begin{tabular}{|c|c|c|c|c|c|}
\hline No. & Cement & Quartz Sand & Waste Glass & Distilled Water & Graphene Oxide \\
\hline 1 & 450 & 990 & 0 & 225 & 0 \\
\hline 2 & 450 & 891 & 99 & 225 & 0 \\
\hline 3 & 450 & 693 & 297 & 225 & 0 \\
\hline 4 & 450 & 495 & 495 & 225 & 0 \\
\hline 5 & 450 & 297 & 693 & 225 & 0 \\
\hline 6 & 450 & 99 & 891 & 225 & 0.225 \\
\hline $4-1$ & 450 & 495 & 495 & 225 & 0.45 \\
\hline $4-2$ & 450 & 495 & 495 & 225 & 0.90 \\
\hline $4-3$ & 450 & 495 & 495 & 225 & \\
\hline
\end{tabular}


Table 2. Particle size of waste glass aggregate for manufacturing mortar

\begin{tabular}{|c|c|c|c|c|c|}
\hline Size $(\mathrm{mm})$ & $4.75 \sim 2.36$ & $2.36 \sim 1.18$ & $1.18 \sim 0.60$ & $0.60 \sim 0.30$ & $0.3 \sim 0.15$ \\
\hline Content $(\%)$ & 10 & 25 & 25 & 25 & 15 \\
\hline
\end{tabular}

Table 3. Mixing ratio for manufacturing mortar for length change test

(g)

\begin{tabular}{|c|c|c|c|c|c|}
\hline No. & Cement & Quartz Sand & Waste Glass & Distilled Water & Graphene Oxide \\
\hline 1 & 440 & 990 & 0 & 206.8 & 0 \\
\hline 2 & 440 & 891 & 99 & 206.8 & 0 \\
\hline 3 & 440 & 693 & 495 & 206.8 & 0 \\
\hline 4 & 440 & 495 & 693 & 206.8 & 0 \\
\hline 5 & 440 & 297 & 891 & 206.8 & 0 \\
\hline 6 & 440 & 99 & 495 & 206.8 & 0.22 \\
\hline $4-1$ & 440 & 495 & 495 & 206.8 & 0.44 \\
\hline $4-2$ & 440 & 495 & 495 & 206.8 & 0.88 \\
\hline
\end{tabular}

동안 양생한 후 압축강도를 측정하였다.

폐유리 사용에 따른 ASR 반응을 확인하기 위한 길 이 변화율 시험편은 압축강도 제작용 시험편과 동일하 게 시멘트, 혼합수(증류수), 일반 모래 및 폐유리 등을 사용하였으며, 이들 배합비를 Table 3 (시멘트 $440 \mathrm{~g}$, 일 반 모래와 폐유리 $990 \mathrm{~g}$, 혼합수 $206.8 \mathrm{~g}$ )에 나타내었다. 시멘트, 골재 및 혼합수는 mortar mixer를 사용하여 2 분간 혼합하였으며, 혼합이 완료된 모르타르는 길이 변 화율 몰드에 넣은 후, tamper와 미장용 칼을 이용하여 성형하였다. 성형 모르타르는 항온항습기(온도 $20^{\circ} \mathrm{C}$-상 대습도 $90 \%$ )에서 24 시간 동안 양생하였다. 24 시간 양 생 후 모르타르의 초기 길이를 측정하였으며, 곧 바로 $1 \mathrm{~N}$ 농도의 $\mathrm{NaOH}$ 용액에 침적시켰다. 침적 모르타르는 $\mathrm{NaOH}$ 용액 내에서 1일, 2 일, 3 일 동안 유지시킨 후 길이 변화율을 측정하였다. 더불어 일반 모래와 폐유리 를 각각 $50 \%$ 씩 사용하고, 산화 그래핀을 시멘트 중량 대비 $0.05 \%, 0.1 \%, 0.2 \%$ 첨가한 모르타르도 상기와 같이 제조한 후 길이 변화율을 측정하였다.

\section{3. 결과 및 고찰}

\section{1. 산화 그래핀 첨가 시멘트 페이스트 경화체의 수 화특성}

Table 4는 본 연구에서 사용한 산화 그래핀 (GRAPHENEALL社, Lot\# : GO-P-190715)의 성분에 대한 것을 나타낸 것이다. 산화 그래핀 내 탄소는 $65.33 \%$, 산소 $31.31 \%$ 등이 함유하고 있으며, $\mathrm{pH}$ 는 2.87 수준이다. 해당 산화 그래핀에 대한 미세구조를 Fig. 2에 나타내었으며, 입자 크기는 약 $10 \sim 100 \mu \mathrm{m}$ 범위에 존재하였다. 또한 산화 그래핀 표면은 매끈하지 않고 거친 형태로 관찰되었는데, 이는 일반적인 제조법 인 Hummers method 중에 사용되는 $\mathrm{KMnO}_{4}, \mathrm{H}_{2} \mathrm{SO}_{4}$ 용액 등의 영향으로 인해 발생된 것으로 알려져 있 다 ${ }^{10,11)}$.

상기 산화 그래핀을 $0 \%, 0.05 \%, 0.1 \%, 0.2 \%$ 첨가 한 3 일 양생 시멘트 페이스트 경화체의 XRD 패턴을 Fig. 3에 나타내었다. 3일 양생 시멘트 경화체의 주요 피크는 $\mathrm{Ca}(\mathrm{OH})_{2}, \mathrm{CaCO}_{3}, \mathrm{C}_{3} \mathrm{~S} \quad\left(3 \mathrm{CaO} \cdot \mathrm{SiO}_{2}\right), \mathrm{C}_{2} \mathrm{~S}$

Table 4. Information of graphene oxide powder (from. GRAPHENEALL corp.)

\begin{tabular}{|c|c|c|c|c|}
\hline Carbon (\%) & Oxygen (\%) & D/G ratio & XRD 2D value & $\mathrm{pH}$ \\
\hline 65.33 & 31.31 & 1.04 & 9.8 & 2.87 \\
\hline
\end{tabular}




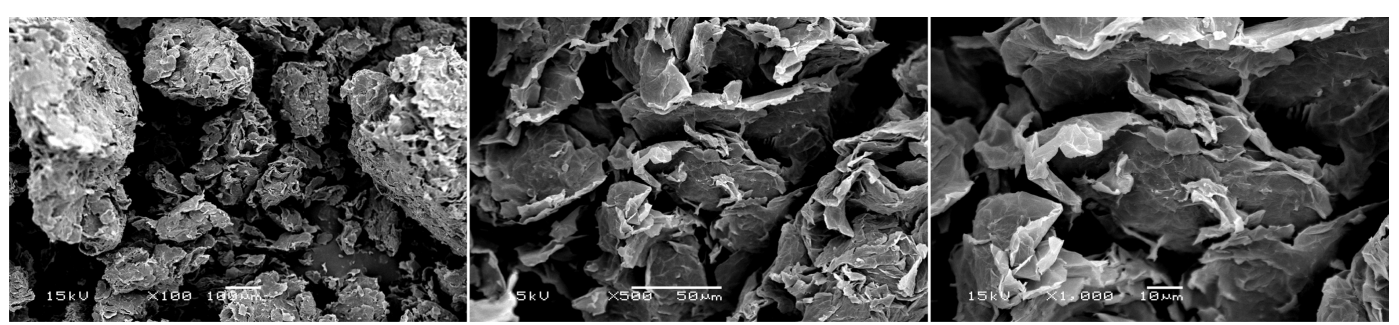

Fig. 2. Morphology of graphene oxide.

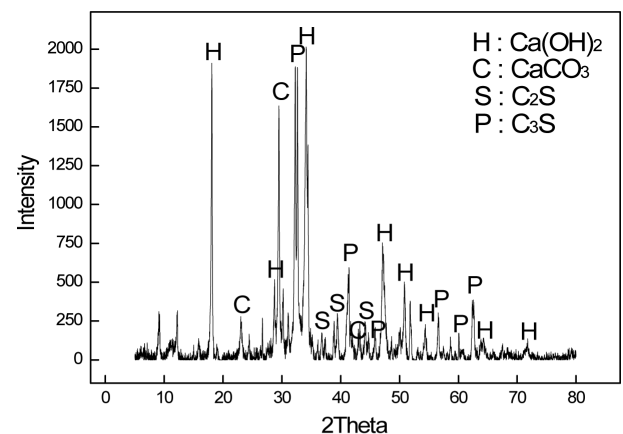

(a) Ref (0\%)

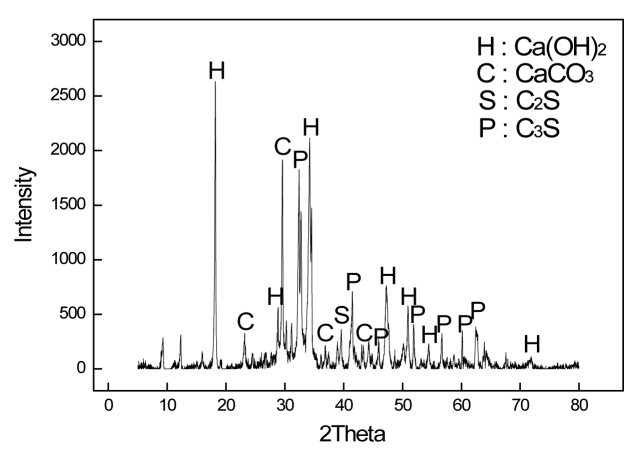

(c) $0.1 \%$

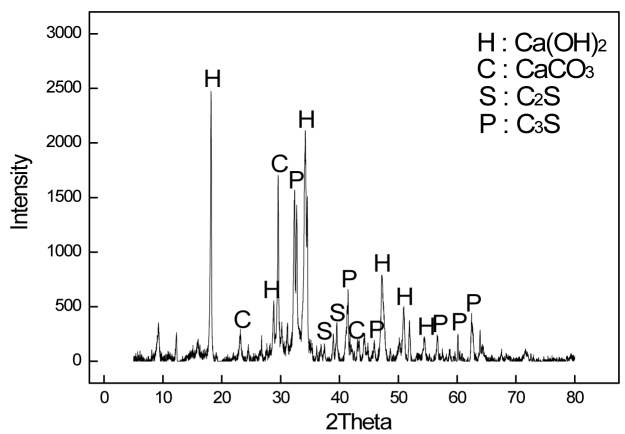

(b) $0.05 \%$

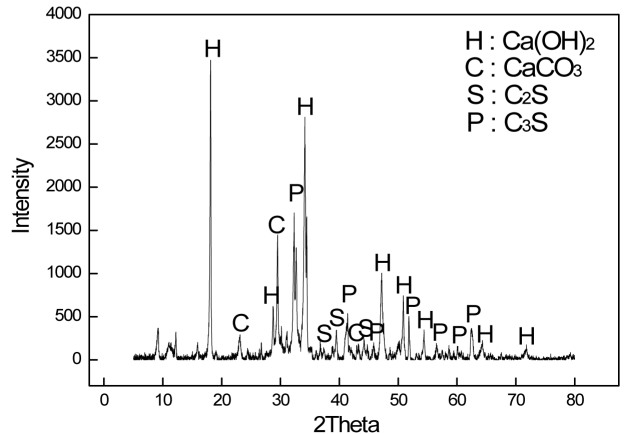

(d) $0.2 \%$

Fig. 3. XRD patterns of cement paste as graphene oxide contents (3 days).

$\left(2 \mathrm{CaO} \cdot \mathrm{SiO}_{2}\right)$ 등으로 확인되었다. 3 일 양생 조건에서는 대표적 시멘트 수화물 중의 하나인 $\mathrm{Ca}(\mathrm{OH})_{2}$ 생성을 확 인할 수 있었으나, 아직 수화반응에 참여하지 않은 클 링커 광물 $\left(\mathrm{C}_{3} \mathrm{~S}, \mathrm{C}_{2} \mathrm{~S}\right)$ 도 존재하는 것으로 판단되었다. 특히 $18^{\circ}(2 \Theta$ 기준 $)$ 에 위치한 $\mathrm{Ca}(\mathrm{OH})_{2}$ 피크 강도(Peak Intensity)는 일정한 경향성을 나타내었다. 즉 산화 그래 핀 첨가량 증가에 따라 $\mathrm{Ca}(\mathrm{OH})_{2}$ 피크 강도는 $1910 \mathrm{CPS}$ (Count Per Second), 2473CPS, 2635CPS, 3459CPS 로 상승하는 경항을 발현하였다. 이는 상기에서 언급한 바와 같이, 산화 그래핀이 시멘트 수화반응 과정에서 수 화물의 핵생성 및 핵성장을 가속화 하는 등, 수화반응
을 촉진시켜 수화물 생성량이 증가하기 때문으로 판단 된다.

3일 양생 시멘트 경화체와 동일하게 제조된 7일 양생 시멘트 경화체의 XRD 패턴을 Fig. 4에 나타내었다. 3 일 양생 시멘트 경화체와 유사하게 주요 피크는 $\mathrm{Ca}(\mathrm{OH})_{2}$, $\mathrm{CaCO}_{3}, \mathrm{C}_{3} \mathrm{~S}\left(3 \mathrm{CaO} \cdot \mathrm{SiO}_{2}\right), \mathrm{C}_{2} \mathrm{~S}\left(2 \mathrm{CaO} \cdot \mathrm{SiO}_{2}\right)$ 등으로 확인되었다. 또한 산화 그래핀 첨가량 증가에 따라 $\mathrm{Ca}(\mathrm{OH})_{2}$ 피크 강도는 상승하는 것으로 검출되었다 $(0 \%-$ 2958CPS, 0.05\%-3565CPS, 0.1\%-4897CPS， 0.2\%$5426 \mathrm{CPS})$. 이에 따라 본 연구에서도 산화 그래핀은 시 멘트 수화반응에 기여할 수 있는 대표적 소재 중의 하 


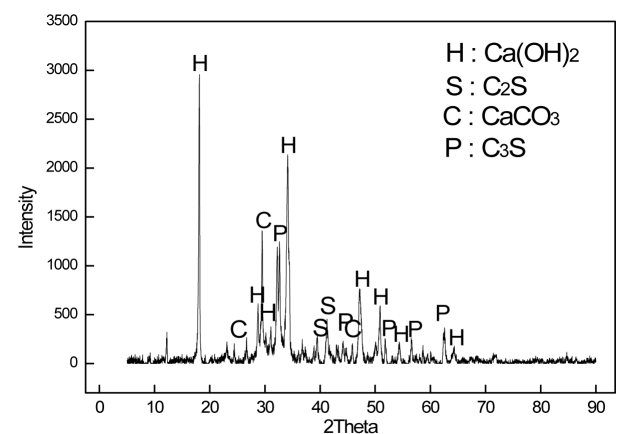

(a) Ref (0\%)

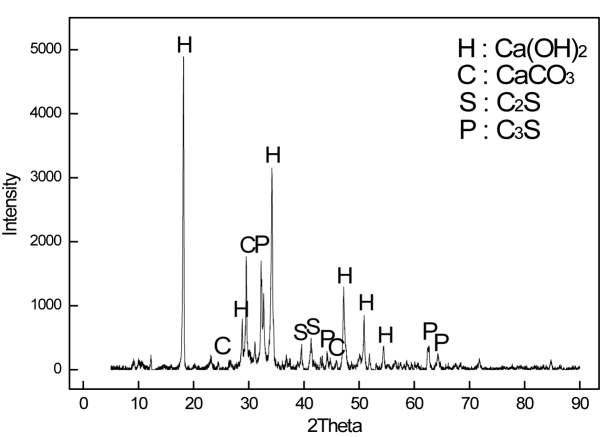

(C) $0.1 \%$

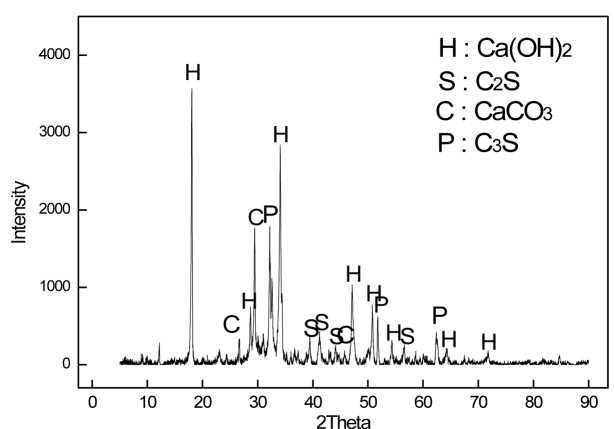

(b) $0.05 \%$

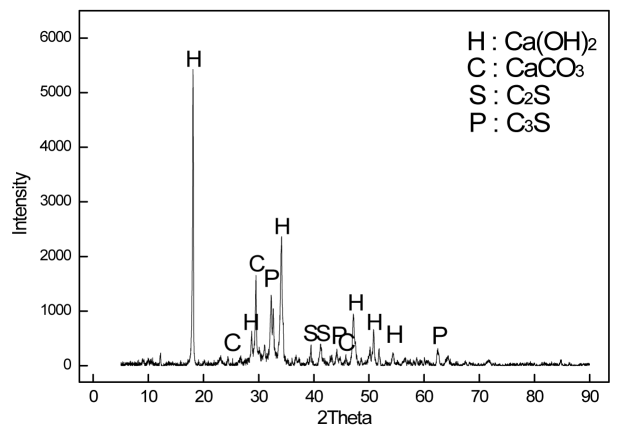

(d) $0.2 \%$

Fig. 4. XRD patterns of cement paste as graphene oxide contents ( 7 days).

나라는 것을 확인할 수 있었다.

7일 양생 시멘트 경화체의 미세구조를 Fig. 5에 나타 내었으며, Fig. 5(a)는 산화 그래핀을 첨가하지 않은 Ref. 경화체, Fig. 5(b)는 산화 그래핀을 $0.2 \%$ 첨가한 경화체의 미세구조이다. 일반적으로 시멘트 경화체에는 Fig. 5-(a)와 같이 에트링자이트 $\left(\mathrm{Ca}_{6} \mathrm{Al}_{2}\left(\mathrm{SO}_{4}\right)_{3}(\mathrm{OH})_{12}\right.$ $\left.\cdot 26 \mathrm{H}_{2} \mathrm{O}\right), \mathrm{Ca}(\mathrm{OH})_{2}, \mathrm{C}-\mathrm{S}-\mathrm{H}\left(\mathrm{CaO}-\mathrm{SiO}_{2}-\mathrm{H}_{2} \mathrm{O}\right)$ 등과 같 은 다양한 시멘트 수화물이 생성되는데, 이들 수화물은 시멘트 모르타르 및 콘크리트의 물리적 특성에 영향을 주는 것으로 알려져 있다. 산화 그래핀을 첨가한 시멘 트 경화체(Fig. 5(b))에서는 상기의 시멘트 수화물들이 관찰되었으며, 더불어 수화반응에 참여한 산화 그래핀 도 관찰되었다. 이는 산화 그래핀이 친수성 용매에서 시 멘트 등의 세라믹 분말과 쉽게 복합화가 가능하다는 특 성도 발현된 것으로 추정되었다 ${ }^{12)}$. Zhu Pan et al.에 따르면, 산화 그래핀은 카르복시산 그룹을 함유하고 있 는데, 이는 C-S-H 또는 $\mathrm{Ca}(\mathrm{OH})_{2}$ 와 반응을 한다. 이러 한 반응은 산화 그래핀과 시멘트 매트릭스 계면에 강한 공유 결합을 형성시켜 계면 접착을 강하게 한다. 결과 적으로, 산화 그래핀 첨가시 모르타르 및 콘크리트의 물
리적 특성 (압축강도 등)을 더욱 향상시키는 것으로 발 표되고 있다 ${ }^{16)}$.

\section{2. 폐유리 및 산화 그래핀을 사용한 모르타르의 물 리적 특성}

Fig. 7은 폐유리와 산화 그래핀을 사용한 모르타르의 3일 및 7일 압축강도 특성을 나타낸 것이다. Fig. 7(a) 는 일반 모래와 폐유리 함량을 제어하여 제조한 모르타 르 압축강도, Fig. 7(b)는 폐유리 $50 \%$ 고정 조건에서 산화 그래핀 함량을 제어한 모르타르 압축강도이다.

3 일 양생 조건에서의 Ref.(일반 모래) 모르타르 압축 강도는 $6.5 \mathrm{~N} / \mathrm{mm}^{2}$ 이었으며, 폐유리 $10 \%$ 대체 모르타 르의 압축강도는 $10.4 \mathrm{~N} / \mathrm{mm}^{2}$ 수준으로 소폭 상승하였 다. 하지만 폐유리 $30 \%$ 및 $50 \%$ 대체의 경우, 압축강 도는 $20.8 \mathrm{~N} / \mathrm{mm}^{2}$ 및 $29.0 \mathrm{~N} / \mathrm{mm}^{2}$ 대폭 상승하였다. 하지만 폐유리 $70 \%$ 대체 시에는 $30.0 \mathrm{~N} / \mathrm{mm}^{2}, 90 \%$ $30.3 \mathrm{~N} / \mathrm{mm}^{2}$ 으로 상승 폭이 감소하였다. 7일 양생 시에 는 각각의 폐유리 대체 조건에서 $10.6 \mathrm{~N} / \mathrm{mm}^{2}, 12.0$ $\mathrm{N} / \mathrm{mm}^{2}, 29.7 \mathrm{~N} / \mathrm{mm}^{2}, 37.8 \mathrm{~N} / \mathrm{mm}^{2}, 41.1 \mathrm{~N} / \mathrm{mm}^{2}$ 및 $39.0 \mathrm{~N} / \mathrm{mm}^{2}$ 이었다. 이는 3 일 양생 모르타르와 유사한 


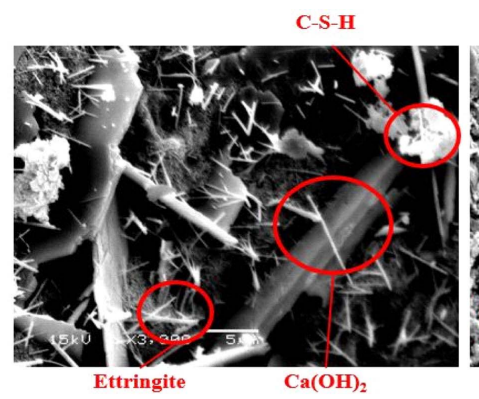

Graphene Oxide

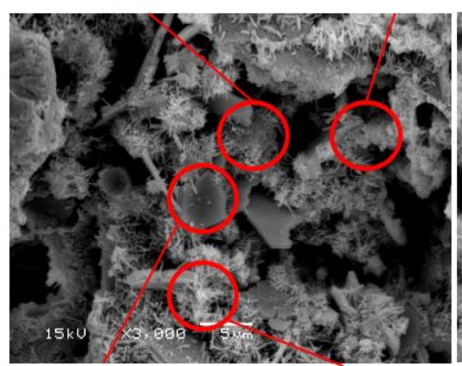

$\mathrm{Ca}(\mathrm{OH})_{2}$ Ettringite

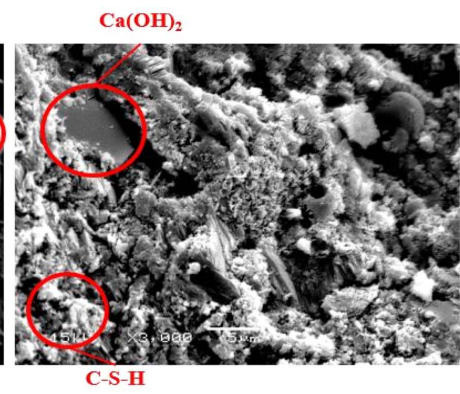

(a) $\operatorname{Ref}(0 \%)$

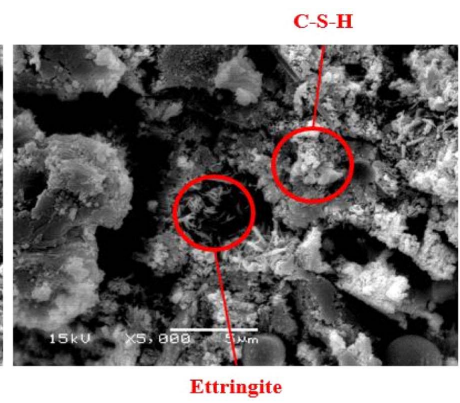

Ettringite

$\mathrm{Ca}(\mathrm{OH})_{2} \quad$ Graphene Oxide

Ettringite

Graphene Oxide

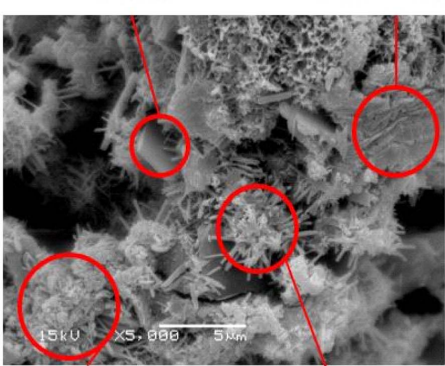

C-S-H

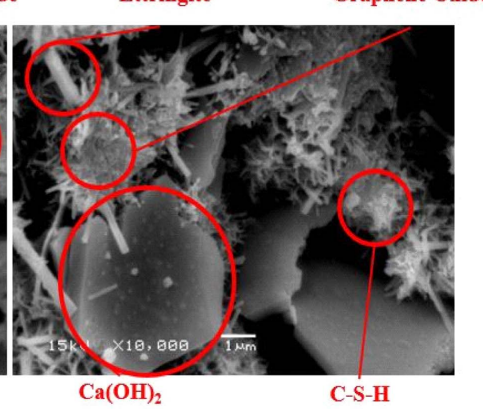

(b) Graphene oxide $0.2 \%$

Fig. 5. Morphology of cement paste with $0 \%$ and $0.2 \%$ graphene oxide.

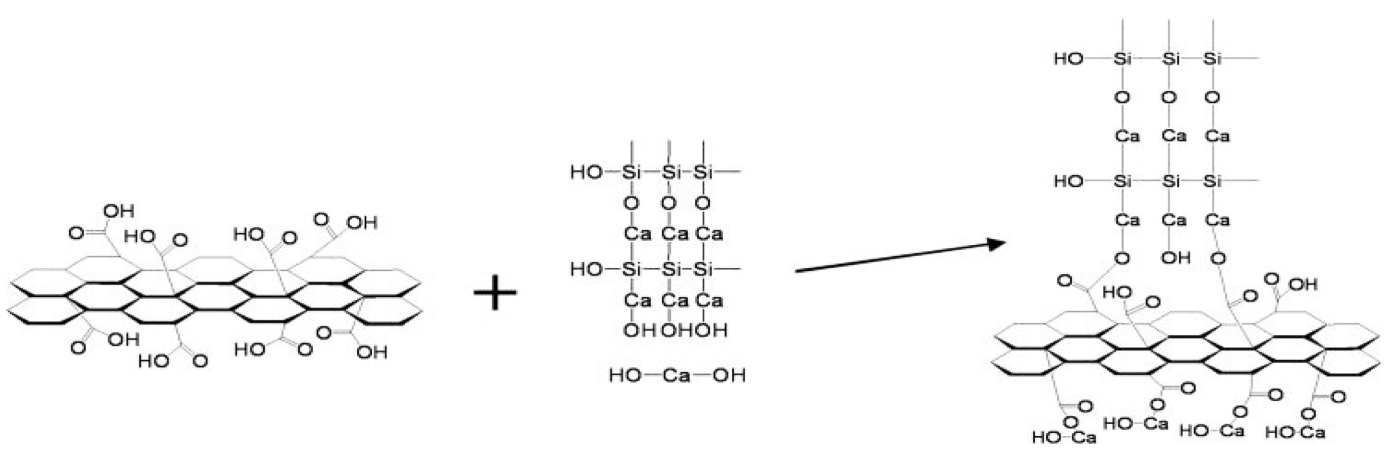

Fig. 6. Schematic reaction between graphene oxide and hydration products of cement ${ }^{16)}$.

경향이었으나, 폐유리 대체량이 $90 \%$ 로 상승될 경우에 는 압축강도가 소폭 감소하기도 하였다. 이와 같은 폐 유리 사용량 증가에 따른 압축강도 상승은 입도가 제어 된 폐유리 사용에 따라 모르타르 충전효과 도출 및 결 정질 모래를 대체한 비정질 실리카인 폐유리 사용으로 수화반응이 촉진되었기 때문으로 사료되었다.

일반 모래 및 폐유리 사용량을 각각 $50 \%$ 로 고정하 고, 산화 그래핀 첨가량을 제어한 모르타르의 3 일 및 7 일 압축강도를 Fig. 7에 나타내었다. 3일 압축강도는 산화 그래핀 함량 $0 \%, 0.05 \%, 0.1 \%, 0.2 \%$ 에서 각각
$29.0 \mathrm{~N} / \mathrm{mm}^{2}, 30.4 \mathrm{~N} / \mathrm{mm}^{2}, 31.0 \mathrm{~N} / \mathrm{mm}^{2}, 32.6 \mathrm{~N} / \mathrm{mm}^{2}$ 로 소폭씩 증가하는 경향을 나타내었다. 또한 7일 양생 시에도 산화 그래핀 첨가량에 따라 각각 $37.9 \mathrm{~N} / \mathrm{mm}^{2}$, $39.0 \mathrm{~N} / \mathrm{mm}^{2}, 40.9 \mathrm{~N} / \mathrm{mm}^{2}, 42.6 \mathrm{~N} / \mathrm{mm}^{2}$ 로, 3 일 강도와 유사한 증가 경향을 나타내었다. 이는 상기에서 언급한 바와 같이 산화 그래핀이 시멘트 수화반응에 참여하여 모르타르 매트릭스를 강화하기 때문으로 추정되었다.

Fig. 8은 폐유리 대체량에 따른 양생일별 길이 변화 율을 나타낸 것이며, 이때 일반 모래 사용 모르타르의 길이변화율을 1.00 으로 기준하여 계산한 결과 값이다. 


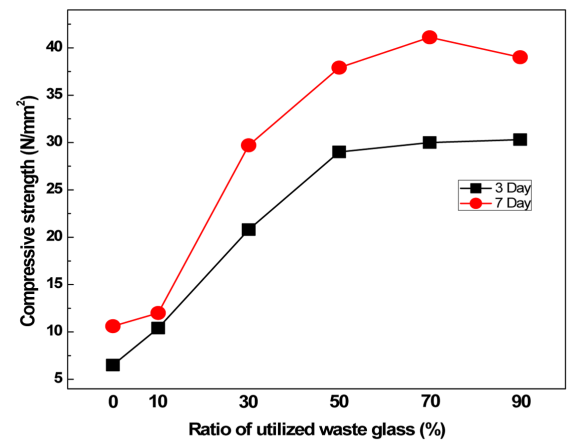

(a) Compressive strength as waste glass contents

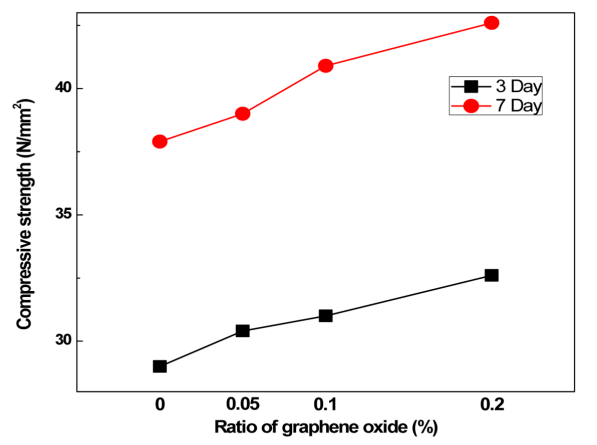

(b) Compressive strength as graphene oxide contents with $50 \%$ waste glass

Fig. 7. Compressive strength as waste glass and graphene oxide contents.

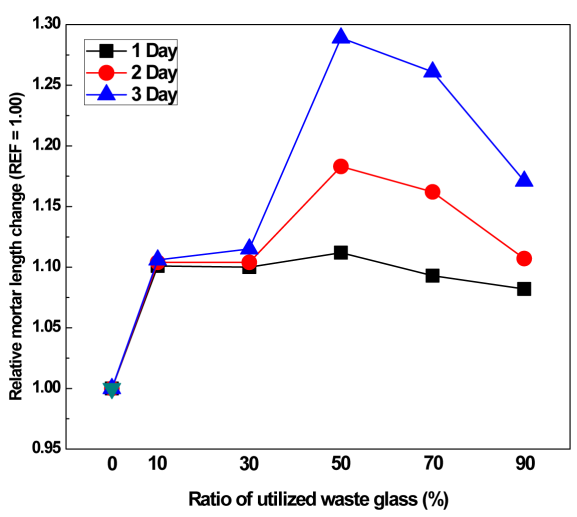

Fig. 8. Result of mortar length change from various ratio of utilized waste glass.

$1 \mathrm{~N} \mathrm{NaOH}$ 수조에서 1일 양생 시 Ref. 대비 0.08 0.11 수준이 팽창되었으며, 수조 양생 2 일 및 3 일의 경

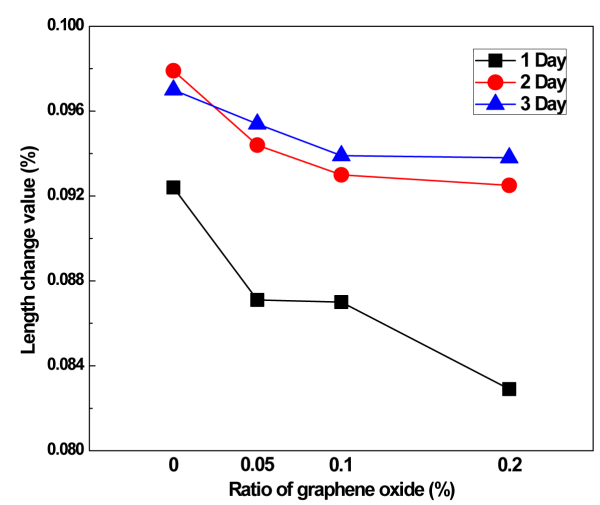

(a) Normal sand
우에는 Ref. 대비 $0.10 \sim 0.18$ 및 $0.11 \sim 0.29$ 수준 이 팽창되었다. 폐유리 사용량 증가에 따라 길이 변화 율 및 양생일별 간의 증가 폭 또한 상승하였으며, 폐유 리 $50 \%$ 대체시에 최대 팽창특성이 발현되었다. 그러나 폐유리 사용량이 $50 \%$ 이상일 경우에는 모르타르 팽창 특성은 점차 감소하였으며, 3 일 양생 기준 폐유리 사용 량 $90 \%$ 에서는 0.17 를 나타내었다. 일반적으로 ASR 반 응이 활발히 이루어지는 경우, 모르타르 내 균열 발생 정도가 높아져 압축강도가 감소되며, 구조체가 팽창하 는 경향이 있당. 일반 모래 성분 내 $\mathrm{SiO}_{2}$ 함량은 80 97\% 수준으로 알려져 있으며, 이는 '규사(quartz sand)' 라고도 일컫는다. 폐유리 사용량 증가에 따라 시 멘트 내 주요 알칼리 성분인 $\mathrm{Na}^{+}$이온, 모래 내 $\mathrm{Si}^{4+}$ 이온 간의 $\mathrm{ASR}$ 과 더불어 폐유리 내 알칼리 성분인 $\mathrm{Na}^{+}$이온이 촉매 역할을 하여 반응에 더욱 큰 기여를

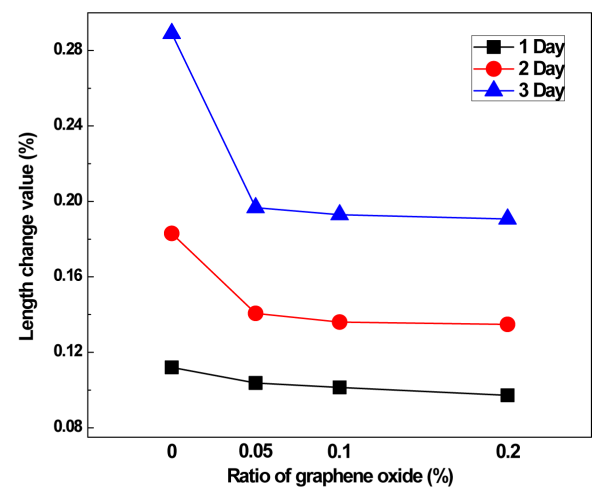

(b) Substitute for waste glass 50\%

Fig. 9. Result of mortar length change as graphene oxide contents. 
하는 것으로 사료된다 ${ }^{4)}$ 하지만 입도가 제어된 폐유리 함량이 증가할수록 모르타르 충전 효과는 더욱 증가하 며, 이에 따라 이온 이동도 제한될 수 밖에 없을 것이 다. 더불어 비정질 폐유리는 수화반응에도 참여하여 이 온 이동 억제 효과가 도출되는 것으로 판단되었다 ${ }^{17,18)}$. 이에 따라 폐유리 사용량이 $50 \%$ 이상일 경우에는 오히 려 팽창성능을 상쇄하는 것으로 추정되었다.

산화 그래핀 첨가량에 따른 모르타르 길이 변화율을 Fig. 9에 나타내었으며, Fig. 9(a)는 일반 모래 사용 모 르타르, (b)는 폐유리 $50 \%$ 사용 모르타르의 길이 변화 율이다. 일반 모래 사용 모르타르의 양생일별 길이 변 화율은 산화 그래핀 첨가량이 증가할수록 감소하는 경 향을 나타내었다. 더불어 폐유리 $50 \%$ 사용시에도 산화 그래핀 첨가량 증가에 따라 길이 변화율은 감소하였다. 일반적으로 $\mathrm{ASR}$ 을 감소시키는 방법으로 C-S-H 및 CA-S-H gel을 이용하여 알칼리를 흡수·고정시키는 방법 이 있다 ${ }^{19,20,21,22)}$. 본 연구에서 사용한 산화 그래핀도 시멘트 수화물 내에 낮은 $\mathrm{pH}$ 분위기 조성 및 이에 따 른 수화반응 촉진으로 C-S-H 수화물 생성량을 증대시 켜 알칼리 이온들을 고정시키거나 ${ }^{7,23)}$, 친수성(hydrophilic)을 가지는 산화 그래핀의 높은 흡습력 및 수화 반응성으로 인해 기공 형성을 억제시켜 모르타르 내 이 온 이동을 방해하는 것으로 판단되었다 ${ }^{24,25)}$.

\section{4. 결 론}

본 연구에서는 국내에서 폐기되는 폐유리를 골재로 사용하여 모르타르를 제조하고자 하였으며, 이때 모르 타르의 길이변화율 및 강도 특성을 분석하였다. 또한 산 화 그래핀을 첨가하여 모르타르 팽창 제어 특성도 검토 하고자 하였으며, 이를 통해 다음과 같은 결과를 도출 하였다.

1. 산화 그래핀 첨가량 증가에 따라 시멘트 경화체의 $\mathrm{Ca}(\mathrm{OH})_{2}$ 피크 강도가 상승하고, 미세구조 관찰시에도 산화 그래핀 입계에서 수화반응이 진행된다는 것을 확 인할 수 있었다. 따라서 산화 그래핀은 시멘트 수화반 응에 기여할 수 있는 소재라는 것을 확인할 수 있었다.

2. 폐유리 사용량 증가에 따라 모르타르 압축강도는 큰 폭으로 상승하는 경향을 나타내었으며, 이는 폐유리 입도특성 및 수화반응성에 기인하는 것으로 사료되었다. 또한 폐유리 사용량 $50 \%$ 모르타르는 산화 그래핀 첨가 량 증가에 따라 압축강도가 비례적으로 상승하였다. 이 는 산화 그래핀 자체의 우수한 강도특성 뿐만 아니라
시멘트 수화물과의 계면반응에 기인하기 때문이다.

3. 폐유리 사용량 증가에 따라 모르타르 길이 변화율 은 증가하였으며, 폐유리 사용량 $50 \%$ 조건에서 최대 팽창하였다. 하지만 폐유리 사용량이 $50 \%$ 이상일 경우 에는 오히려 팽창성이 감소하였다. 이는 시멘트 내 주 요 알칼리 성분인 $\mathrm{Na}^{+}$이온, 모래 내 $\mathrm{Si}^{4+}$ 이온 간의 기본 알칼리-실리카 반응과 더불어 폐유리 내 알칼리 성분인 $\mathrm{Na}^{+}$이온이 촉매 역할을 하여 $\mathrm{ASR}$ 에 기여하기 때문이다.

4. 폐유리 $50 \%$ 사용 모르타르는 산화 그래핀 첨가량 증가에 따라 길이 변화율이 감소하는 경향을 나타내었 다. 이는 산화 그래핀이 시멘트 수화반응 촉진작용을 일 으켜 수화물 생성량을 증대시키고, 이들 수화물은 모르 타르 내 이온 이동을 방해하기 때문으로 추정되었다. 따 라서 산화 그래핀은 폐유리로부터 기인하는 팽창특성을 일부 제어할 수 있는 것으로 판단되었다.

\section{References}

1. Ministry of Environment of Korea, 2018 : Resource Recycling Law, Public document.

2. Ministry of Environment of Korea, 2019 : Waste Management Act Enforcement Rules, Public document.

3. KEITI, 2018 : Development Status of Domestic and Overseas Recycling Demand for Waste Glass Bottles, Public document.

4. Stephane Multon, Alain Sellier, and Martin Cyr, 2009 : Chemo-mechanical modeling for prediction of alkali silica reaction (ASR) expansion, Cement and Concrete Research, 39(6), pp.490-500.

5. Farshad Rajabipour, Eric Giannini, and Cyrille Dunant, 2015 : Alkali-silica reaction : Current understanding of the reaction mechanisms and the knowledge gaps, Cement and Concrete Research, 76, pp.130-146.

6. Joao Feiteira and Maria S. Ribeiro, 2013 : Polymer action on alkali-silica reaction in cement mortar, Cement and Concrete Research, 44, pp.97-105.

7. T. T. H. Bach, E. Chabas, and I. Pochard, 2013 : Retention of alkali ions by hydrated low-pH cements: Mechanism and $\mathrm{Na}^{+} / \mathrm{K}^{+}$selectivity, Cement and Concrete Research, 51, pp.1893-1903.

8. Taehwan Kim, Jan Olek, and HyunGu Jeong, 2015 : Alkali-silica reaction : Kinetics of chemistry of pore solution and calcium hydroxide content in cementitious system, Cement and Concrete Research, 71, pp.36-45.

9. Sardar Kashif UrRehman, Zainah Ibrahim, and Shazim Ali Memon, 2017 : A Sustainable Graphene Based Cement 
Composite, Sustainability, 9(7), pp.1-20.

10. Sungjin Park and Rodney S. Ruoff, 2009 : Chemical methods for the production of graphenes, Nature Nanotechnology, 4(4), pp.217-224.

11. Yanwu Zhu, Shanthi Murali, and Weiwei Cai, 2010 : Graphene and Graphene Oxide: Synthesis, Properties, and Applications, Advanced Materials, 22(35), pp.3906-3924.

12. Virendra Singh, Daeha Joung, and Lei Zhai, 2011 : Graphene based materials: Past, present and future, Progress in Materials Science, 56(8), pp.1178-1271.

13. Qin Wang, Jian Wang, and Chun-xiang Lu, 2015 : Influence of graphene oxide additions on the microstructure and mechanical strength of cement, New Carbon Materials, 30(4), pp.349-356.

14. Kai Gong, Zhu Pan, and Asghar H. Korayem, 2015 : Reinforcing Effects of Graphene Oxide on Portland Cement Paste, Journal of Materials in Civil Engineering, 27(2), pp.1-6.

15. Xiangyu Li, Asghar Habibnejad Korayem, and Chenyang Li, 2016 : Incorporation of graphene oxide and silica fume into cement paste: A study of dispersion and compressive strength, Construction and Building Materials, 123, pp.327-335.

16. Zhu Pan, Li He, and Ling Qiu : Mechanical properties and microstructure of a graphene oxide-cement composite, Cement and Concrete Composites, 58, pp.140-147.

17. M. Aly, M. S. J. Hashmi, and A. G. Olabi, 2012 : Effect of colloidal nano-silica on the mechanical and physical behaviour of waste-glass cement mortar, Materials \&

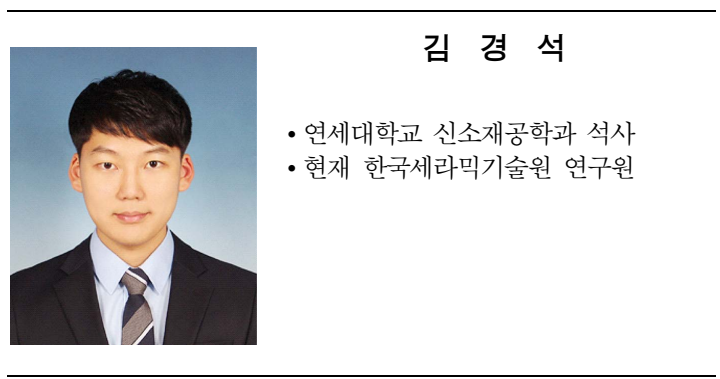

Design, 33, pp.127-135.

18. M. Aly, M. S. J. Hashmi, and A. G. Olabi, 2011 : Effect of nano clay particles on mechanical, thermal and physical behaviours of waste-glass cement mortars, Materials Science and Engineering: A, 528(27), pp.7991-7998.

19. Sung-Yoon Hong and F. P. Glasser, 1999 : Alkali binding in cement pastes Part 1. The C-S-H phase, Cement and Concrete Research, 29(12), pp.1893-1903.

20. W. Chen and H. J. H. Brouwers, 2010 : Alkali binding in hydrated Portland cement paste, Cement and Concrete Research, 40(5), pp.716-722.

21. Theodore Chappex and Karen Scrivener, 2012 : Alkali fixation of C-S-H in blended cement pastes and its relation to alkali silica reaction, Cement and Concrete Research, 42(8), pp.1049-1054.

22. E. L. Hopital, B. Lothenbach, K. Scrivener, and D. A. Kulik, 2016 : Alkali uptake in calcium alumina silicate hydrate (C-A-S-H), Cement and Concrete Research, 85, pp.122-136.

23. M. H. Al-Khaldi, H. A. Nasr-El-Din, and S. Mehta, 2007 : Reaction of citric acid with calcite, Chemical Engineering Science, 62(21), pp.5880-5896.

24. B. Lian, S. De Luca, and Y. You, 2018 : Extraordinary water adsorption characteristics of graphene oxide, Chemical Science, 11, pp.1-6.

25. Vira Agieienko, Vadim Neklyudov, and Ayrat Dimiev, 2019 : Solvent-induced changes in the graphene oxide absorption spectrum. The case of dimethylsulfoxide/water mixtures, Journal of Molecular Liquids, 287, 110942.

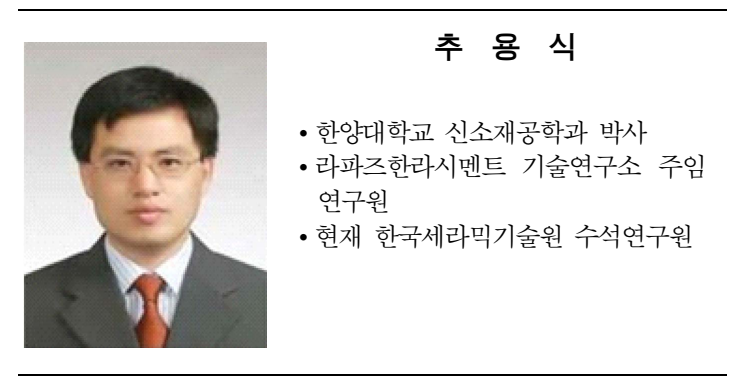

